\title{
Effect of naltrexone on senile dementia of the Alzheimer type
}

\author{
BRADLEY T HYMAN, PAUL J ESLINGER, ANTONIO R DAMASIO \\ From the Department of Neurology (Division of Behavioral Neurology), University of Iowa College of \\ Medicine, lowa City, IA, USA
}

SUMMARY Some reports have suggested that naloxone, a short-acting opiate receptor blocker given intravenously, has a beneficial effect on the symptoms of senile dementia of the Alzheimer type. We have performed a double-blind, crossover trial of naltrexone, an orally active, long acting opiate antagonist, in 17 Alzheimer-type dementia patients. None showed any improvement in assessments of day-to-day living skills or on a battery of neuropsychological tests. No side effects were noted. In the dosage used, naltrexone appears not to be useful in Alzheimer-type dementia.

Research on senile dementia of the Alzheimer type has uncovered defects in the noradrenergic, cholinergic, and somatostatinergic transmitter systems but the cause of the disease remains unknown, ${ }^{1-4}$ and there is no effective treatment. Nonetheless, trials with cholinergic precursors and acetylcholinesterase inhibitors have resulted in some improvement and suggested that pharmacological intervention might be beneficial. ${ }^{5}$

Opiate antagonists can influence attention and memory and it has been hypothesised that they may be useful in Alzheimer-type dementia. ${ }^{6}$ Two reports described improvement in some patients with this disorder following intravenous administration of naloxone, a short-acting opiate antagonist. ${ }^{78}$ The results of subsequent trials, however, were disappointing. ${ }^{90}$ Possible causes for the failure of naloxone might include the short half-life of the substance (less than one hour) and the fact that intravenous administration will not maintain a continuous high blood level and a sustained opioid blockade. To find out if such limitations do indeed play a role, we undertook a double-blind cross-over study of naltrexone, a long acting opiate antagonist," that can

Address for reprint requests: Antonio $R$ Damasio, MD PhD, Department of Neurology, University of Iowa Hospitals \& Clinics, Iowa City, IA 52242, USA.

Received 7 December 1984 and in revised form 22 March 1985. Accepted 5 April 1985 be administered orally, and that produces a higher level of opiate blockade than naloxone at equivalent doses. The relatively long half-life of naltrexone, greater than 24 hours, suggests that opiate blockade can be maintained continuously for days when an oral dosing regimen is followed.

\section{Methods}

\section{Subjects}

Seventeen patients with Alzheimer-type dementia were recruited for this study ( 7 male; 10 female). All had extensive neurological, neuropsychological, and neuroradiological studies which were consistent with Alzheimer-type dementia. Only those patients who could understand and complete neuropsychological tests were included. Length of illness ranged from 1 to 15 years $(4.4 \pm 3.4$ years, mean $\pm S E$ ). Ages ranged from 57 to 81 years, with a mean of 67.5 years. Five had a positive family history for dementia. One patient did not attend the last session (placebo) because of agitation, apparently unrelated to the study.

\section{Procedures}

Informed consent was obtained from the patients and their families. Patients were given either $100 \mathrm{mg} /$ day naltrexone $\mathrm{HCl}$, by mouth (courtesy of Du Pont, Inc.) or placebo, each week, during a six-week double blind crossover study. Active medication was administered during either the second or fourth week of the study. Blood pressure, heart rate and weight were monitored at each session. Each week patients were also evaluated by a battery of neuropsychological tests, the family was interviewed to assess 
Table Effect of naltrexone and placebo on behavioural measures

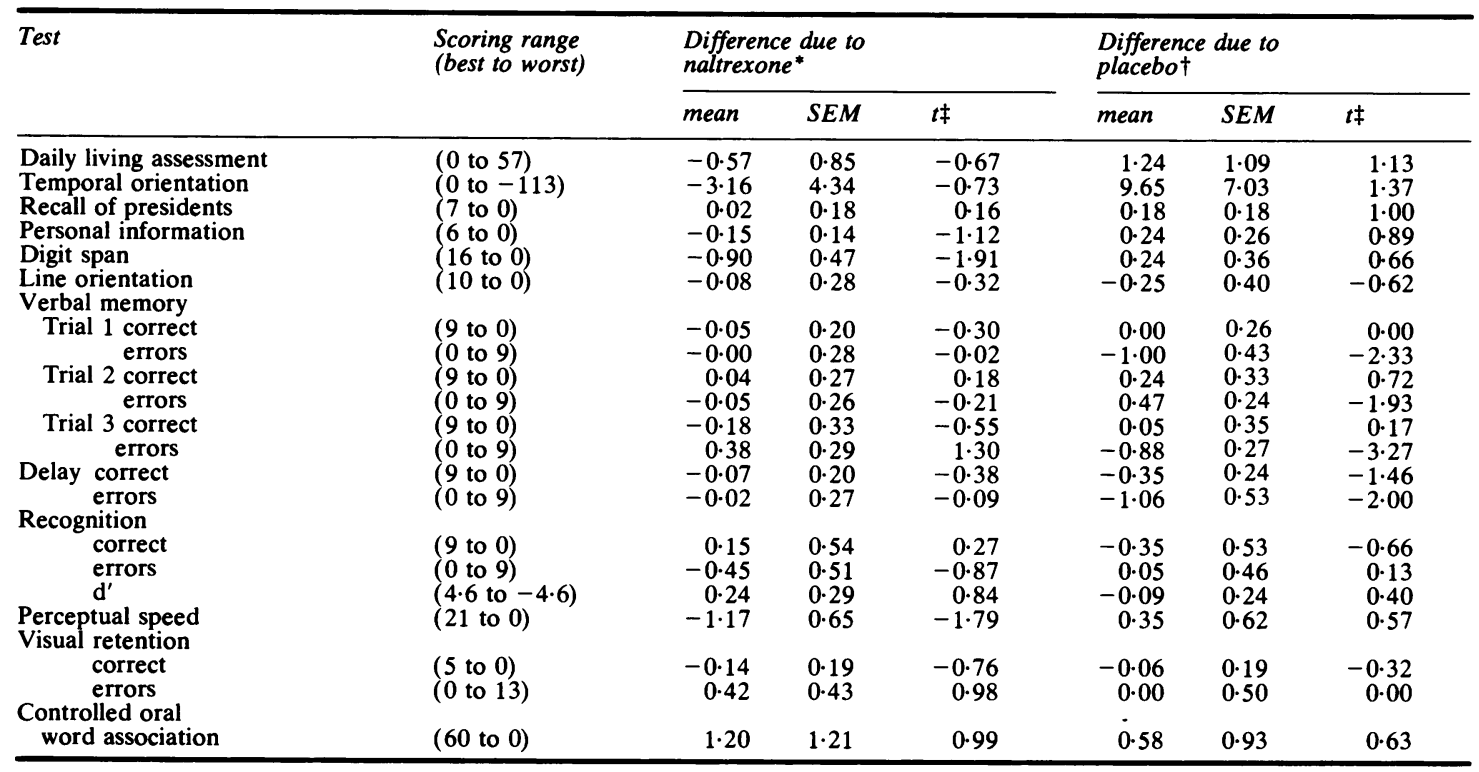

${ }^{*}$ Calculated as mean of placebo scores $(n=4)$ minus the naltrexone score.

†Calculated as placebo score (session 2) minus the no medication score (session 1).

$\ddagger$ For 16 degrees of freedom, using Bonferroni's correction for multiple comparisons, tcrit $=3.686$ ( $p<0.05$ ).

side effects and changes in day-to-day function, and a daily living assessment questionnaire was filled in by the family. The Hamilton depression and anxiety scales were (completed) at initial interview and after the second and fourth weeks.

The neuropsychological battery ${ }^{12}$ included measures of:(1) Orientation to time, place and personal information; (2) Immediate memory for digits (digit span); (3) Verbal learning and memory in which subjects recalled a nine word list in a multiple trial, free recall format. Five minute delayed recall and recognition trials were included; (4) Visual memory for designs in which subjects were required to reproduce a geometric design after a 10 second exposure period. Five trials were adapted from the Visual Retention test; (5) Visuospatial judgment in which subjects were required to judge the orientation of lines in a matching to sample procedure. Ten trials were administered; (6) Perceptual Speed in which subjects were required to cross out a particular digit appearing 21 times among seven lines of 29 digits each. The dependent measure was number correct in 45 seconds; (7) Controlled Oral Word Association in which subjects orally generated words beginning with a given letter of the alphabet within a minute time period. Three letters were administered. This battery was designed in six parallel forms, and order of presentation of these forms was randomized for each patient.

For each patient, mean test scores were calculated from the four placebo trials. This mean was then compared to performance on the naltrexone trial by means of a $t$ test. Level of statistical significance $(p<0.05)$ was adjusted using Bonferroni's correction for multiple comparisons. Difference scores were also computed for naltrexone vs placebo trials as well as for no medication (initial test ses- sion) vs placebo trials. These scores were then analysed for the entire group of 17 patients by means of $t$ tests, which were interpreted using Bonferroni's correction for multiple comparisons.

\section{Results}

As a group, the patients demonstrated no significant statistical change in performances on the neuro-? psychological battery, daily living questionnaire and Hamilton scales following naltrexone treatment. Family members did not report any consistent improvement during the week of naltrexone treatment. For example, during naltrexone treatment the results of the daily living questionnaire showed slight improvement in nine patients, worsening in seven, and no change in one. As a group, after treatment with naltrexone as compared to placebo, the patients' mean performance level was slightly higher on eight tasks of the neuropsychological battery and worse on 11 tasks; however, none of the difference scores reached statistical significance (table), even without correction for multiple comparisons. Similarly, comparison of performance at baseline (initial testing session, no medications) vs placebo (week 1) revealed no significant placebo effects.

Test scores after naltrexone therapy were also compared for each patient on an individual basis. In only one case was a significant difference found, and that one patient performed in the reverse direction, 
more poorly, on the digit span test after naltrexone than after placebo $(t=10.1, p<0.001)$. This patient did not have significant differences on any other task.

The medication was well tolerated by all patients. No side effects were noted by the family or patients. No significant changes in heart rate, blood pressure, or weight occurred with naltrexone therapy, either in an individual patient or across the group.

\section{Discussion}

The effect of opiate antagonists on learning and memory is not yet fully understood. In young, normal volunteers high doses of naloxone $(2 \mathrm{mg} / \mathrm{kg}$, IV) has decreased performance on a delayed word recall and recognition task, but had no effect on immediate memory. ${ }^{13}$ Lower doses $(0.03 \mathrm{mg} / \mathrm{kg})$ of naloxone have been linked to increased selective attention in man. ${ }^{14}$ In the rat, naloxone has been shown to attenuate the amnesia caused by amygdaloid stimulation ${ }^{15}$ or electroconvulsive shock. ${ }^{16}$ Naltrexone has been shown to have an effect similar to naloxone, by increasing retention of passive avoidance tasks. ${ }^{17}$

In this study, we assessed the efficacy of naltrexone in the possible amelioration of memory and other cognitive deficits characteristic of Alzheimertype dementia. Our results show that this intervention produced no improvement. Nonetheless, since our intervention was based on a single dosage schedule, for one week only, it remains possible that alternative dosage regimens may uncover some effect of long term opiate antagonists. Finally, we did not encounter any major side effects of naltrexone administration in this group of patients.

We thank Du Pont, Inc. for the generous gift of naltrexone $\mathrm{HCl}$ and placebo tablets, the Clinical Research Center clinical staff and support personnel for assistance, Dr A Lachenbruch for advice on statistical analyses, and J Carter for secretarial assistance.

This work was supported by a grant from The Mathers Foundation, grant RR59 from the General Clinical Research Center Branch of the NIH, and, in part, by Research Fellowship 1 F32 EY05720.

\section{References}

' Terry RD, Katzman R. Senile dementia of the
Alzheimer type. Ann Neurol 1983;14:497-506.

${ }^{2}$ Iversen LL, Rosser MN, Reynolds GP, et al. Loss of pigmented dopamine B-hydroxylase positive cells from locus coeruleus in senile dementia of Alzheimer's type. Neurosci Lect 1983;39:95-100.

${ }^{3}$ Davies R, Maloney AJR. Selective loss of central cholinergic neurons in Alzheimer's disease. Lancet 1976;2: 1403.

${ }^{4}$ Davies R, Katzman R, Terry RD. Reduced somatostatin-like activity in cerebral cortex from cases of Alzheimer's disease and Alzheimer senile dementia. Nature 1980;288:279-80.

' Thal LS, Fuld PA, Masur DM, Sharpless NS. Oral physostigmine and lecithin improve memory in Alzheimer's disease. Ann Neurol 1983;13:491-6.

${ }^{6}$ Roberts E. A speculative consideration on the neurobiology and treatment of senile dementia. In: Crook T, Gershon S, eds. Strategies for the Development of an Effective Treatment for Senile Dementia. New Canaan (CT): Mark Powley Associates, Inc, 1981:247-320.

${ }^{7}$ Reisberg B, Ferris SH, Anand R, Mir P, de Leon MJ, Roberts E. Naloxone effects on primary degenerative dementia (PDD). Psychopharm Bull 1983;19:44-7.

${ }^{8}$ Reisberg B, Ferris SH, Anand R, et al. Effects of naloxone in senile dementia: a double-blind trial. $N$ Engl J Med 1983;308:721-2.

${ }^{9}$ Blass JP, Reding MJ, Drachman D, et al. Naloxone in dementia. $N$ Engl J Med 1983;309:556.

${ }^{10}$ Panella JJ, Blass JP. Lack of clinical benefit from naloxone in a dementia day hospital. Ann Neurol 1984; 15:308.

"Willette RE, Barnett G, eds. Naltrexone Pharmacochemistry and Sustained-Release Preparations. National Institute on Drug Abuse Research Monograph, 1981, 28. US Government Printing Office, Washington, DC.

${ }^{12}$ Benton AL, Hamsher K, Varnes N, Spreen O. Contributions to Neuropsychological Assessment. Oxford University Press, 1983, New York.

${ }^{13}$ Cohen RM, Cohen MR, Weingartner H, Pickar P, Murphy DC. High-dose naloxone affects task performance in normal subjects. Psych Res 1983;8:127-36.

${ }^{14}$ Arnsten AFT, Segal DS, Neville HJ, et al. Naloxone augments electrophysiological signs of selective attention in man. Nature 1983;304:725-7.

is Liang KC, Messing RB, McGaugh JL. Naloxone attenuates amnesia caused by amygdaloid stimulation: the involvement of a central opioid system. Brain Res 1983;271:41-9.

${ }^{16}$ Carrasio MA, Dias RD, Izquierdo I. Naloxone reverses retrograde amnesia induced by electroconvulsive shock. Behav Neurol Biol 1982;34:352-7.

${ }^{17}$ Gallagher M. Naloxone enhancement of memory processes. Effects of other opiate antagonists. Behav Neurol Biol 1982;35:375-82. 